\title{
EFFECT OF CINNAMON AND GINGER METHANOLIC EXTRACTS ON MURINE INTESTINAL CRYPTOSPORIDIOSIS.IN-VIVO EVALUATION
}

\author{
By \\ EMAN MAGDY FAWZY ${ }^{1}$, RABAB SAYED ZALAT ${ }^{2}$, HAYAM ELSAID RASHED ${ }^{3}$ \\ MARWA AHMED SALAMA ${ }^{1}$, AMIRA A. SALEH ${ }^{1}$, and \\ ENAS FAKHRY ABDELHAMED ${ }^{1^{\star}}$
}

Department of Medical Parasitology ${ }^{1}$, Faculty of Medicine, Department of Parasitology ${ }^{2}$, Theodor Bilharz Research Institute, Embaba, Giza and Department of

Pathology ${ }^{3}$, Faculty of Medicine, Zagazig University ${ }^{1,3}$, Egypt ( ${ }^{*}$ Correspondence: enas_refae1983@yahoo.com; ORCID ID:0000-0002-4039-2710)

\begin{abstract}
Cryptosporidium species the Apicomplexa protozoan parasites, causing diarrheal disease in man and animals, due to the lack of a licensed vaccine and resistance to the available effective therapy. This study explored the curative and the prophylactic effect of the cinnamon and ginger methanolic extracts separately and combined with nanazoxide on the experimentally infected mice with Cryptosporidium. Ninety Swiss albino mice, weight of 23-25gm, aged 7-8 weeks were divided into nine groups to assess the therapeutic and the prophylactic effect of cinnamon and ginger methanolic extracts separately then combined with nanazoxide. The result was assessed parasitologically, histopathlogically and by TEM. The best efficacy was three weeks post infection in all groups. Therapeutic effect of ginger was better than cinnamon extract, but combined ginger and nanazoxide gave the least oocyst shedding. The prophylactic dose of ginger and cinnamon methanolic extracts showed marked decrease in oocysts shedding and ginger was the best. Histopathological sections showed immune cells infiltration with a decrease in number of tissue parasite that was absent in the prophylactic groups given ginger extract. The results were confirmed by transmission electron microscopy explored a great improvement in the small intestinal brush border of the same groups.
\end{abstract}

Keywords: Cryptosporidium, cinnamon-ginger, transmission electron microscopy

\section{Introduction}

Cryptosporidium species (spp.) are protozoan parasites that cause diarrheal disease in humans and animals (Tzipori and Ward, 2002). In immunocompromised individuals, Cryptosporidium represents a serious health problem (Breurec et al, 2016). Nitazoxanide which is the traditional treatment for cryptosporidiosis is ineffective especially in immunocompromised individuals (Amadi et al, 2009).

Due to the lack of a licensed vaccine and the effective drugs for cryptosporidiosis with the emergence of resistance to the available therapeutics, it was indicated to search for effective anti-parasitic drugs (Ryan et al, 2016). A number of medicinal plant extracts have more antiparasitic effect than the currently used drugs (El-Sayed and Issa, 2008). Through the intervening with the process of intercalation or alkylation of the parasite DNA, the plant extracts have a remarkable effect. Also, they can inhibit the membrane integrity and the neural signal transduction of the target parasite (El-Sayed et al, 2012).

Cinnamon is a popular spice, obtained from the inner bark of trees being a member of the genus Cinnamomum. It has different synonyms as Cinnamomum zeylanicum (CZ) and Cinnamon cassia (CC) (Shen et al, 2002). Cinnamon has many active constituents including cinnamaldehyde compounds (bark), eugenol (leaf), camphor (root), volatile oils, tannins, mucilage, limonene, and safrole that possess an antibacterial, antiseptic, antiviral, and antifungal properties (Gruenwald et al, 2010; Cahyana et al, 2015). It revealed that different extracts of cinnamon were effective against bacteria, yeast, Leishmania, and Toxoplasma as well (Senhaji et $a l, 2005)$. Its leaves exhibit an immunomodulatory, anti-inflammatory, anti-parasitic, and antioxidant properties (Anthony et al, 2005). It also improves the immune system 
and reduces the risk of colon cancer (Wondrak et al, 2010).

Zingiber officinale Roscoe (Ginger) is commonly used as a nutrient remedy (Surh 1999). The oily resin of roots contains many bioactive components, as gingerol, shogaol, paradol, zingerone, zerumbone, 1-dehydro(10)-gingerdione, terpenoids, and flavonoid ds. They have antioxidant activities, anti-inflammatory, antimicrobial, and liver-protecting activities (Arshad et al, 2014). Ginger can be used as an anti-parasitic for overcoming drug-resistance in parasitic diseases. It has an anti-protozoal effect against Toxoplasma gondii (Choi et al, 2013), Giardia lamblia (Mahmoud et al, 2014), Blastocystis spp. (Abdel-Hafeez et al, 2015), and Trypanosoma spp. (Kobo et al, 2014).

The study aimed to explore the curative effect of cinnamon and ginger methanolic extracts separately and combined with nanazoxide and the prophylactic capability of these herbal extracts on the experimentally infected mice with Cryptosporidium.

\section{Material and Methods}

Stool samples were collected from patients suffering from diarrhea or any GIT troubles attending the outpatient clinics of Zagazig University Hospitals. Fresh fecal samples were collected and preserved in formalin $10 \%$. The direct smear, the formol ether concentration technique and the permanent mount using modified Ziehl-Neelsen stain were done for each sample. Positive samples for Cryptosporidium were collected, preserved in potassium dichromate $2.5 \%$, and then stored at $4^{\circ} \mathrm{C}$.

Oocyst isolation: Fecal specimens were washed then filtrated. The filtered solution was centrifuged at $2500 \mathrm{rpm}$ for 5 minutes twice for washing and removing potassium dichromate. To the sediment, $20 \mathrm{ml}$ of distilled water and $20 \mathrm{ml}$ of diethyl ether were added mixed and then centrifuged at 2500 rpm for 5 minutes and this step was done twice. The sediment was washed with distilled water and saturated water with sugar was added and was centrifuged at $2500 \mathrm{rpm}$ for 5 minutes. In this method, C. parvum oocysts were floated and gathered with a pipette and stored in distilled water with $0.5 \%$ sodium hypochlorite (Hadfield et al, 2015).

Mice: Ninety Swiss albino mice were all free from any parasitic infection, weight of 23-25gm, aged 7-8 weeks obtained from the Schistosome Biological Supply Program (SBSP) in Theodor Bilharz Research Institute (TBRI) Cairo, Egypt.

Immunosuppression: The synthetic corticosteroids (dexamethasone) were used for immunosuppression of mice in a dose of 20 $\mathrm{mg} / \mathrm{kg} /$ day intramuscularly 3 times a week for 3 weeks for each mouse prior to the oocysts inoculation (Rasmussen and Healey, 1992). The mice continued to receive dexamethasone at the same dose throughout the experiment.

Infection: All mice were infected orally (intraesophageal) with prepared Cryptosporidium oocysts; after day 21 of dexamethasone administration. About 1000 oocysts in $200 \mu 1$ of phosphate-buffered saline (PBS) /mouse were given (Benamrouz et al, 2012).

Plant material: Dried Cinnamomum ver$u m$ and dried rhizomes of Zingiber officinale were purchased from a local herbal shop (Cairo, Egypt). The plant samples were grounded to a fine powder with an electric mill for the extraction process.

Extraction of plants: Dried Cinnamo-mum verum $(500 \mathrm{gm})$ and dried of Zingiber officinale $(500 \mathrm{gm})$ was soaked separately in $85 \%$ methanol for one week then, the Cinnamomum verum extract was filtered several times via Whatman No.1 filter paper then concentrated via the Buchi Rotatory evaporator at $400 \mathrm{C}$ to remove methanol completely; same process was repeated to Zingiber officinale extract.

Nanazoxide administration and medicinal plant preparation: Nanazoxide (obtained from Medizen pharmaceutical industries for Utopia pharmaceuticals) is given 7 days (PI) in a dose of $100 \mathrm{mg} / \mathrm{kg}$ body weight $(0.04 \mathrm{mg}$ /mouse/day) for seven consecutive days. Methanolic extract of both herbs was given 
7 days (PI) in a dose of $20 \mathrm{mg} / \mathrm{kg} / \mathrm{d}$ for seven consecutive days.

Experimental design: This experiment was carried out in Theodor Bilharz Research Institute (TBRI) Cairo, Egypt. The infected immunocompromised mice were divided into eight groups each contain ten mice and there was one normal non-infected group: GI: infected control (infected not treated). GII: infected and treated with nanozoxide 0.04mg/mouse/day. GIII: infected and treated with methanolic extract of cinnamon plant $20 \mathrm{mg} / \mathrm{kg} / \mathrm{d}$. GIV: infected and treated with methanolic extract of ginger $20 \mathrm{mg} / \mathrm{kg} /$ day. GV: infected and treated with a combination of a half dose of nanozoxide and methanolic extract of cinnamon $20 \mathrm{mg} / \mathrm{kg} / \mathrm{d}$. GVI: infected and treated with a combination of a half dose of nanozoxide and methanolic extract of ginger $20 \mathrm{mg} / \mathrm{kg} / \mathrm{d}$. GVII: given prophylaxis with methanolic extract of cinnamon $20 \mathrm{mg} / \mathrm{kg} / \mathrm{d}$. one week before infection then continuing its administration throughout infection and 1 week PI. GVIII: given prophylaxis with methanolic extract of ginger $20 \mathrm{mg} / \mathrm{kg} / \mathrm{d}$. one week before infection then continuing its administration throughout infection and 1 week PI, \& GIX: Control negative

Parasitological assessment (oocyst count in stool samples): Fresh fecal pellets from each mouse in the studied groups were collected separately and examined daily then the mean numbers of the oocysts were calculated at the $7^{\text {th }}$ day PI (to assess infection establishment), $14^{\text {th }}$ day PI (1-week posttreatment) and $21^{\text {st }}$ day PI (2weeks posttreatment) before mice scarification, according to each group. Each sample was suspended in $10 \%$ formalin and homogenized. Approximately, $1 \mathrm{mg}$ was prepared as a fecal smear to be stained with the modified Ziehl-Neelsen staining method. The stained fecal smear was examined microscopically and number of Cryptosporidium oocysts was counted.

Histopathological examination: The jeju- num and proximal $2 \mathrm{~cm}$ of the ileum were fixed in $10 \%$ neutral buffered formalin followed by immersion in xylene then impregnated in paraffin. 4-mm thick section was taken from each block to be stained with hematoxylin and eosin for evaluation, (Bancroft and Stevens, 1990).

Transmission Electron Microscope: 1Thin $1 \mathrm{~mm}$ section of each sample was prepared, 2- Sample was fixed in Cacodylate $0.2 \mathrm{M}+$ Gluteraldehyde $4 \%$ in $\mathrm{PH} 7.4$ \& 4c for 2 hours, and 3-Sample was washed in Caccodylate $0.2 \mathrm{M}+$ Saccharose $0.4 \mathrm{M}$ three times in a washer for 30min. then left till the next day, Post-fixation in 2\% Osmic acid (1 Vol.)+ Caccodylate 0.3M (1Vol.) at PH 7.4 and $4 \mathrm{c}$.

Statistical analysis: Data were analyzed by (SPSS; version 20 for windows). All data were expressed as mean \pm standard deviation. Difference between groups was calculated using Student's $t$-test.

Ethical considerations: Informed consent was taken from all patients before taking fecal samples. The experimental animal studies were conducted in accordance with the international valid guidelines and they were maintained with convenient conditions. The study was approved by the University Ethical Committee.

\section{Results}

A highly statistically significant difference was between all studied groups at different follow up periods PI. Within each week PI, the difference between the all studied groups was highly significant. As the best results were obtained on the third week PI, the therapeutic effects of cinnamon and ginger extracts on mean numbers of oocysts $(19 \pm 1.49$ $\& 14 \pm 1.39$ respectively), were highly significant compared with nanozoxide $(27 \pm 2)$. But, combination between nanozoxide and either cinnamon or ginger $(11.4 \pm 1.07 \&$ $9 \pm 1.49$ respectively), gave the best results among treated groups. As to prophylactic effect, the ginger extract $(0.80 \pm 0.07)$ was better than cinnamon extract $(1.8 \pm 0.77)$. 
Histopathological changes (Fig. 1b, c) showed the developmental stage of $C$. parv$u m$ in the affected intestinal villi, subepithelial cell edema, atrophy and sloughing of the upper tips of some villi with inflammatory cells infiltration, and focal cystic dilation present inside the intestinal lumen of the infected group. GVII given a prophylactic dose of cinnamon methanolic extract, showed a moderate inflammatory cellular infiltration in submucosa (Fig. 1 d). GVIII given a prophylactic dose of ginger methanolic extract gave a mild inflammatory cellular infiltration in submucosa but no $C$. parvum (Fig. 1e).

The TEM of ultrathin section of murine small intestinal epithelial cells revealed the luminal surface of columnar cells with Cryptosporidium trophozoite incarcerated in between the microvilli with restoration of the normal villi architecture in GVIII given the prophylactic doses of the ginger extract (Fig 2 e) when compared with the infected control GI, that showed a complete loss of microvilli, presence of Cryptosporidium meront containing merozoites, degenerated cells with dark small nuclei, rarified cytoplasm, degenerated organelles, and the mature Cryptosporidium oocyst with clear double wall (Fig. 2 c, d).

The details were given in table (10 and figures $(1 \& 2)$

Table 1: Effect of different plants extracts on mean numbers of oocysts in groups

\begin{tabular}{|l|c|c|c|c|}
\hline Variable & One week PI $(\mathrm{n}=10)$ & Two weeks PI $(\mathrm{n}=10)$ & Three weeks PI $(\mathrm{n}=10)$ & $\mathrm{P}$ \\
\hline Group I & $80.8 \pm 2.34$ & $81.5 \pm 3.5$ & $82 \pm 2.6$ & $0.645(\mathrm{NS})$ \\
\hline Group II & $77 \pm 4.05$ & $40.8 \pm 2.52$ & $27 \pm 2$ & $<0.001(\mathrm{HS})$ \\
\hline Group III & $76 \pm 4.5$ & $36.8 \pm 2.25$ & $19 \pm 1.49$ & $<0.001(\mathrm{HS})$ \\
\hline Group IV & $74.6 \pm 4.45$ & $30 \pm 1.49$ & $14 \pm 1.39$ & $<0.001(\mathrm{HS})$ \\
\hline Group V & $77.8 \pm 4.07$ & $20 \pm 1.49$ & $11.4 \pm 1.07$ & $<0.001(\mathrm{HS})$ \\
\hline Group VI & $74.2 \pm 5.09$ & $17 \pm 2.10$ & $9 \pm 1.49$ & $<0.001(\mathrm{HS})$ \\
\hline Group VII & $45.2 \pm 5.59$ & $9 \pm 1.39$ & $1.8 \pm 0.77$ & $<0.001(\mathrm{HS})$ \\
\hline Group VIII & $40.4 \pm 4.97$ & $6 \pm 2.2$ & $0.80 \pm 0.07$ & $<0.001(\mathrm{HS})$ \\
\hline P\#1: & $0.001(\mathrm{HS})$ & $<0.001(\mathrm{HS})$ & $<0.001(\mathrm{HS})$ & \multicolumn{2}{|c|}{ Student's t-test }
\end{tabular}

\section{Discussion}

Cryptosporidiosis is one of the most common infectious diarrheal illnesses in immunocompromised individuals worldwide. In developing countries, Cryptosporidium spp. is the second leading cause of infectious diarrheal diseases in children under the age of 5 years (Gebretsadik et al, 2018).

In this study, prophylactic and curative effects of methanolic extracts of ginger \& cinnamon in a dose of $20 \mathrm{mg} / \mathrm{kg} /$ day for Cryptosporidium infected mice compared to the nanazoxide assessed by the oocyst shedding rate, histopathological examination was confirmed by the TEM.

In the present study, oocyst shedding was decreased in groups III, IV, V, VI respectively. The best results were obtained on the third week PI, in which, the therapeutic effects of cinnamon and ginger extracts on the oocysts mean numbers $(19 \pm 1.49 \& 14 \pm 1.39$ respectively), were significantly lower than that of nanozoxide $(27 \pm 2)$. Ginger gave better results than cinnamon. The combination of ginger and nanazoxide gave the lowest oocyst shedding. These results may be due to the anti-oxidant action of ginger which helps in the elimination of parasites (Sadhana and Gupta, 2013). A complete eradication of $C$. parvum oocysts on the $9^{\text {th }}$ day PI was reported by Abouel-Nour et al. (2016), when ginger and metronidazole were used in the experimentally infected mice. Failure of the parasitic growth, its sexual development and the loss of oocyst development may be the mechanism of action. The difference in results may be due to different drugs. Choi et al. (2013) concluded that ginger extract has an effect against Toxoplasma gondii by inactivation of the apoptotic proteins within parasitized host cells, in addition to the blockage of inflammatory cytokine secretion. 
Also, the ginger was approved to be safe for human uses (Rong et al, 2009). Maximum oocyst shedding was seen in the infected not treated ones, which agreed with Certad et al. (2007) and Abdou et al. (2013).

The highest oocysts shedding reduction rate was observed in treated prophylactically with methanolic extract of cinnamon and treated prophylactically with methanolic ginger extract after $1 \& 2$ weeks, reached the best on the $3^{\text {rd }}$ week PI $(1.8 \pm 0.77$ and $0.80 \pm 0.07$, respectively). This may be due to the anti-oxidant effect of cinnamon and ginger that helped in the parasites elimination (Sadhana and Gupta, 2013). Abu El Ezz et al. (2011) reported that both of onion (Allium cepa) and cinnamon (C. zeylanicum) oils induced a significant reduction in $C$. parvum oocysts count.

The general biological action of cinnamon on extracts induced lipid peroxidation, generation of anti-proliferative, the antioxidant effects and detoxication of enzymes (Kumar et al, 2006). Also, the secretory system of Toxoplasma gondii treated with cinnamon extracts suffered a drastic disorganization and vesiculation (Melo et al, 2011).

Ginger anti-inflammatory effects may be due to inhibiting prostaglandin and leukotriene synthesis (Srivastava and Mustafa, 1992). The 6-gingerol was found to inhibit the production of proinflammatory cytokines such as TNF- $\alpha$, interleukin (IL)-1 $\beta, \&$ IL-12, produced by macrophages (Tripathi et al, 2007). Majority of scientific evidences suggested that ginger and its components have anti-inflammatory effects in vitro and in vivo as well.

The present histopathological results of infected control showed sub-epithelial cell edema, atrophy and sloughing of the upper tips of some villi with inflammatory cells infiltration. These findings agreed with Gookin et al. (2002) and Mahmood et al. (2016). An explanation for the pathological changes was that Cryptosporidium displaced brush borders causing loss of epithelial cells which leads to shortening, sloughing and fusing of the villi. A previous explanation was that Cryptosporidium toxins damage the epithelial cells (Tzipori, 2002). On the other hand, there was a remarkable decrease in the number of Cryptosporidium oocysts in the epithelial brush border in GVII \& GVIII given prophylactic doses. The results were compatible with Harp et al. (1996) who reported that plant oils might block receptor sites on the surface of small intestinal villi, thus leading to a reduction in Cryptosporidium parvum colonization. Both extracts failed to restore the normal symmetrical architecture of ileal villi and mucosa completely. But, inflammatory cellular infiltration indicated that the immunity increased in the mucosa of the intestine. This may be attributed to the immune stimulant of cinnamon containing eugenol with the local antiseptic and antiphagocytic properties (Wondrak et al, 2010). This agreed with Lantier et al. (2013) who reported that immune cell induction and maintenance in infected intestine for protection against $C$. parvum. Also, Abouel-Nour et al. (2016) reported that supplementation of ginger to infected mice implied its potential antioxidant, anti-inflammatory, and immunomodulatory effects. Abu El Ezz et al. (2011) found that cinnamon oil improved the ileal villi, where the parasite colonized as the villi in treated mice retained their normal appearance.

In the present study, by TEM the small intestinal epithelial cells of the normal control had regular oval euchromatic nuclei, numerous apical microvilli, and the welldeveloped cell junctions, as well as a crypt containing goblet cells with numerous mucous granules that may coalesce. Regarding the infected untreated mice, there was a complete loss of microvilli, degenerated cells with dark small nuclei, rarified cytoplasm, and degenerated organelles, cryptosporidium meront containing merozoites and immature Cryptosporidium oocyst with a clear double-wall measuring $5 \mu \mathrm{m}$ was detected. Pohlenz et al. (1978) reported that many of the microvilli adjacent to parasite 
are short; others are elongated; some rootlets of microvilli are missing. Microvilli of neighboring cells are normal shaped. Cryptosporidium trophozoite incarcerated inbetween the microvilli with shortening of these adjacent microvilli and restoration of normal villi architecture away from the parasite was observed in mice received prophylactic doses of ginger extract. The intracellular immune cell infiltration, regeneration of MV \& remained stages of parasite was detected in mice received prophylactic doses of cinnamon extract.

\section{Conclusion}

The study may be the first challenge to investigate the curative effect of ginger and cinnamon alone and combined with the nanazoxide and the prophylactic effect of these herbs against murine cryptosporidiosis using TEM. Prophylactic and curative effects of methanolic extracts of ginger and cinnamon in a dose of $20 \mathrm{mg} / \mathrm{kg} /$ day gave variable but promising anti-cryptosporidial activity in infected mice. They could be used as a natural safe product for the preparation of a new therapeutic agent. Combination of nanazoxide and ginger or cinnamon gave good effects. The isolation and the purification of the bioactive components of them will be a future project.

\section{References}

Abdel-Hafeez, EH, Ahmad, AK, Kamal, A M, Abdellatif, MZ, Abdelgelil, NH, 2015: In vivo anti-protozoan effects of garlic (Allium sativum) and ginger (Zingiber officinale) extracts on experimentally infected mice with Blastocystis spp. Parasitol. Res. 114, 9:3439-44.

Abdou, AG, Harba, NM, Afifi, AF, Elnaida ny, NF, 2013: Assessment of Cryptosporidium parvum infection in immunocompetent and immunocompromised mice and its role in triggering intestinal dysplasia. Int. J. Infect. Dis. 17, 8:e593-600.

Abu El Ezz, NMT, Khalil, FAM, Shaapan, R M, 2011: Therapeutic effect of onion (Allium cepa) and Cinnamon (Cinnamomum zeylanicum) Oils on Cryptosporidiosis in Experimentally Infected Mice. Glob. Vet. 7, 2:179-83.

Abouel-Nour, MF, El-Shewehy, DM, Hamada SF, Morsy TA, 2016: The efficacy of three medicinal plants; garlic, ginger and mirazid and a chemical drug Metronidazole against Cryptosporidium parvum: II-Histological changes. J. Egypt Soc. Parasitol. 46, 1:185-200.

Amadi, B, Mwiya M, Sianongo, S, Payne, L, Watuka, A, et al, 2009: High dose prolonged treatment with nitazoxanide is not effective for cryptosporidiosis in HIV positive Zambian children: a randomized controlled trial. BMC Infect. Dis. 9:195-9.

Anthony, JP, Fyfe, L, Smith, H, 2005: Plant active components: A resource for antiparasitic agents? Trends Parasitol. 21, 10:462-8.

Arshad, HR, Fahad, MA, Salah, MA, 2014: Active ingredients of ginger as potential candidates in the prevention and treatment of diseases via modulation of biological activities. Int. J. Physiol. Pathophysiol. Pharmacol. 6, 2:125-36.

Bahmani, M, Golshahi, H, Mohsenzadegan, A, Ahangarani, MG, Ghasem, E, 2013: Comparative assessment of the anti-Limnatis nilotica activities of Zingiber officinale methanolic extract with levamisole. Comp. Clin. Pathol. 22: 667-0.

Bancroft, ID, Stevens, A, 1990: Theory and practice of histological techniques. Churchill Livingston, Edinburgh, UK. 3rd ed.

Baqer, NN, Khuder, M, Amer, N, 2014: Anti-protoscolices effects of ethanolic extract of Zingiber officinale against Echinococcus granulosus in vitro and in vivo. Int. J. Adv. Res. 2, 10:59-68.

Benamrouz, S, Guyot, K, Gazzola S, Mouray, A, Chassat, T, et al, 2012: Cryptosporidium parvum infection in SCID mice infected with only one oocyst: qPCR assessment of parasite replication in tissues and development of digestive cancer. PLOS ONE 7, 12: e51232.

Breurec, S, Vanel, N, Bata, P, Chartier, L, Farra, A, et al, 2016: Etiology and epidemiology of diarrhea in hospitalized children from low income country: a matched case-control study in Central African Republic. PLoS Neglected Trop. Dis. 10, e0004283

Cahyana, AH, Wibowo, W, Pratama, A, Ardiansah, B, 2015: Synthesis, characterization and anti-oxidative properties of propolis-like compound prepared from prenylation of Indonesia's cinnamon (Cinnamomum burmannii) essential oil using $\gamma-\mathrm{Al}_{2} \mathrm{O}_{3} / \mathrm{NaOH} / \mathrm{Na}$. J. Chem. Pharma. Res. 1:715-9.

Certad, G, Ngouanesavanh, T, Guyot, K, Gantois, N, Chassat, T, et al, 2007: Cryptospo- 
ridium parvum, a potential cause of colic adenocarcinoma. Infect Agent Cancer 2: 22

Choi, WH, Jiang, MH, Chu, JP, 2013: Antiparasitic effects of Zingiber officinale (ginger) extract against Toxoplasma gondii. J. Appl. Bio med. 11:15-26.

El-Sayed, NM, Ismail, KA, Ahmed, SAG, Hetta, MH 2012: In vitro amoebicidal activity of ethanol extracts of Arachis hypogaea L., Curcuma longa L. and Pancratium maritimum L. on Acanthamoeba castellanii cysts. Parasitol. Res. 110, 5:1985-92.

El-Sayed, NM, Issa, RM, 2008: In vitro effect of wheat germ agglutinin and Nigella sativa aqueous extract as natural herbal medication on growth and motility of Trichomonas vaginalis trophozoite in comparison to metronidazole. Egypt J. Med. Sci. 29, 1/2:263-78.

Gebretsadik, D, Metaferia, Y, Seid, A, et al, 2018: Prevalence of intestinal parasitic infection among children under 5 years of age at Dessie Referral Hospital: Cross sectional study. BMC Res. Notes. 11:771.

Gookin, JL, Nordone, SK, Argenzio, RA, 2002: Host responses to Cryptosporidium infection. J Vet Intern Med 16: 12-21.

Gruenwald, J, Freder, J, Armbruester, N, 2010: Cinnamon and health. Crit. Rev. Food Sci. Nutr. 50, 9:822-34.

Hadfield, SJ, Pachebat, JA, Swain, MT, et al, 2015: Generation of whole genome sequences of new Cryptosporidium hominis \& Cryptosporidium parvum isolates directly from stool samples. BMC Genomics 16, 1:650-6.

Harp, JA, Jardon, P, Atwill, ER, Zylstra, MS, Checel, JP, et al, 1996: Field testing of prophylactic measures against Cryptosporidium parvum infection in calves in a California dairy herd. Am. J. Vet. Res. 57:1586-8.

John, DT, Petri, WA, 2006: Medical Parasitology $9^{\text {th }}$ edition. Elsevier Inc. USA.

Kobo, PI, Erin, PJ, Suleiman, MM, Aliyu, H, Tauheed, M, et al, 2014: Anti-trypanosomal effect of methanolic extract of Zingiber officinale (ginger) on Trypanosoma brucei bruceiinfected Wistar mice. Vet. World 7, 10:770-5.

Kumar S1, Suresh PK, Vijayababu MR, Arunkumar A, Arunakaran J, 2006: Anticancer effects of ethanolic neem leaf extract on prostate cancer cell line (PC-3). J. Ethnopharmacol. 105: 246-50.

Lantier, L, Lacroix-Lamande, S, Potiron, L, Metton, C, Drouet, F, et al, 2013: Intestinal
CD 103+ dendritic cells are key players in the innate immune control of Cryptosporidium parvum infection in neonatal mice. PLoS Path. 9: e1003801

Lin, RJ, Chen, CY, Lee, JD, Lu, CM, Chung, LY, et al, 2010: Larvicidal constituents of Zingiber officinale (ginger) against Anisakis simplex. Planta Med. 76, 16:1852-8.

Lin, RJ, Chen, CY, Lu, CM, Ma, YH, Chung, LY, et al, 2014: Anthelmintic constituents from ginger (Zingiber officinale) against Hymenolepis nana. Acta Trop.140:50-60.

Mahmood, NM, Ramadan, FN, Hassan, M S, Sabry, YH, Magdy, MM, 2016: Therapeutic effect of Phoenix dactylifera against cryptosporidiosis in immunocompromised mice. Glob. Adv. Res. J. Med. Sci. 5:88-95.

Mahmoud, A, Attia, R, Said, S, Ibraheim, Z, 2014: Ginger and cinnamon: Can this household remedy treat giardiasis? Parasitological and histopathological studies. Iran. J. Parasitol. 19, 4:530-40.

Massoud, AM, Habib, FS, 2003: The effects of myrrh (Commiphora molmol) on the infected snails of Schistosoma sp. and their egg masses: Effect on shedding of cercariae and on snail fecundity. J. Egypt Soc. Parasitol. 33, 2: 585-96.

Melo, EJT, Vilela, KJ, Carvalho, CS, 2011: Effects of aqueous leaf extracts of Azadirachta indica A. Juss. (Neem) and Melia azedarach L. (Santa barbara or cinnamon) on the intracellular development of Toxoplasma gon-dii. Rev. Bras. Plantas Med. 13:2-8.

Mostafa, OM, Shati, AA, Adly, MA, Bin Dajem, SM, Ibrahim EH, et al, 2012: Assessment of the antischistosomal activity of ginger (Zingiber officinale) against Schistosoma mansoni harbored in C57BL/6 Mice. J. Drug Res. Egypt 33, 1:25-33.

Pohlenzw, J, Bemrickh, J, Moon, W, Cheville, NF, 1978: Bovine cryptosporidiosis: A transmission and scanning electron microscopic study of some stages in the life cycle and of the hostparasite relationship Vet. Pathol. 15: 417-27.

Rasmussen, KR, Healey, MC, 1992: Experimental Cryptosporidium parvum infections in immune-suppressed adult mice. J Infect. Immun. 4:1648-52

Rong X, Peng G, Suzuki T, 2009: A 35-day gavage safety assessment of ginger in rats. Regul. Toxicol. Pharmacol. 54:118-23

Ryan, U, Zahedi, A, Paparini, A, 2016: Crypt- 
osporidium in humans and animals: A one health approach to prophylaxis. Parasite Immunol. 38: 535-47.

Sadhana, S, Gupta, AK, 2013: Evaluation of Phenolics Content, Flavonoids and Antioxidant activity of Curcuma amada (Mango Ginger) and Zingiber officinale (Ginger): Research and Reviews. J. Chem. 2, 1:32-5.

Senhaji O, Faid M, Elyachioui M, 2005: Antibiosis by cinnamon extracts against antibiotic resistant strains. Int. J. Agric. Biol. 7, 5:724-8.

Shen, Q, Chen, F, Luo, J, Zhong, Y, et al, 2002: Comparison studies on chemical constituents of essential oil from Ramulus cinnamomi and Cortex cinnamomi by GC-MS]. Zhong Yao Cai. 25, 4:257-8.

Srivastava, KC, Mustafa, T, 1992: Ginger ( $Z i-$ ngiber officinale) in rheumatism and musculoskeletal disorders. Med. Hypotheses 39, 4:342-8. Surh, Y, 1999: Molecular mechanisms of chemopreventive effects of selected dietary and medicinal phenolic substances. Mutat. Res. 428, 1/2:305-27.

Tripathi, S, Maier, KG, Bruch, D, Kittur, DS, 2007: Effect of [6]-gingerol on pro-inflammatory cytokine production and co-stimulatory mol- ecule expression in murine peritoneal macrophages. J. Surg. Res. 138, 2:209-13.

Tzipori, S, 2002: Introduction. Cryptosporidiosis: Current trends and challenges. Microbes Infect. 4, 10:1045

Tzipori S, Ward H, 2002: Cryptosporidiosis: biology, pathogenesis and disease. Microbes Infect. 4:1047-58.

Waldman E, Tzipori S, Forsyth JRL, 1986: Separation of Cryptosporidium species oocysts from feces by using a percoll discontinuous density gradient. J. Clin. Microbiol., 23: 199-200.

Wink M, 2012: Medicinal plants: A source of anti-parasitic secondary metabolites. Molecules 17:12771-91

Wondrak GT, Villeneuve NF, Lamore SD, Bause AS, Jiang T, Zhang DD, 2010: The cinnamon-derived dietary factor cinnamic aldehyde activates the Nrf2-dependent antioxidant response in human epithelial colon cells. Molecules 15:3338-55.

Zenner L, Callait MP, Granier C, Chauve, C, 2003: In vitro effect of essential oils from Cinnamomum aromaticum, Citrus limon and Allium sativum on two intestinal flagellates of poultry, Tetratrichomonas gallinarum and Histomonas meleagridis. Parasite 10:153-7.

\section{Explanation of Figures}

Fig.1 a. Normal control group showing normal histological structure villi (black arrow), crypt of Lieberkuhn (red arrow) and muscular layers (astriks) $(\mathrm{H} \& \mathrm{E} \times 100) \mathrm{b}$, c infected group showing sub-epithelial cell edema (green arrow), atrophy and sloughing of upper tips of some villi (red arrow) with infiltration of inflammatory cells (black arrow) $(\mathrm{H} \& \mathrm{E} \times 100) \mathrm{d}$. Group VII treated prophylactically with methanolic extract of cinnamon showing moderate inflammatory cellular infiltration in submucosa (arrow)(H\&E $\times 400)$ e. Group VIII treated prophylactically with methanolic extract of ginger showing mild inflammatory cellular infiltration in submucosa $(\mathrm{H} \& \mathrm{E} \times 400)$.

Fig. 2 TEM of ultrathin section of murine small intestinal epithelial cells a, b: normal control murine small intestinal epithelial cells showing columnar cells with regular oval euchromatic nucleus (N), numerous apical microvilli (MV) and well developed cell junctions (arrows). A part of a crypt containing goblet cells (GC), with numerous mucous granules that may coalesce. c, d: small intestinal epithelial cells infected with Cryptosporidium (groupI) showing complete loss of microvilli, Cryptosporidium meront containing merozoites, degenerated cells with dark small nuclei, rarified cytoplasm and degenerated organelles $(\mathrm{O})$, mature Cryptosporidium oocyst with clear double wall. e: showing the luminal surface of columnar cells with Cryptosporidium trophozoite (T) incarcerated in-between the microvilli (MV) and restoration of normal villi architecture ( group VIII) f: showing intracellular immune cell infiltration ( arrows), regeneration of MV and completely destroyed parasite (C) ( group VII). 

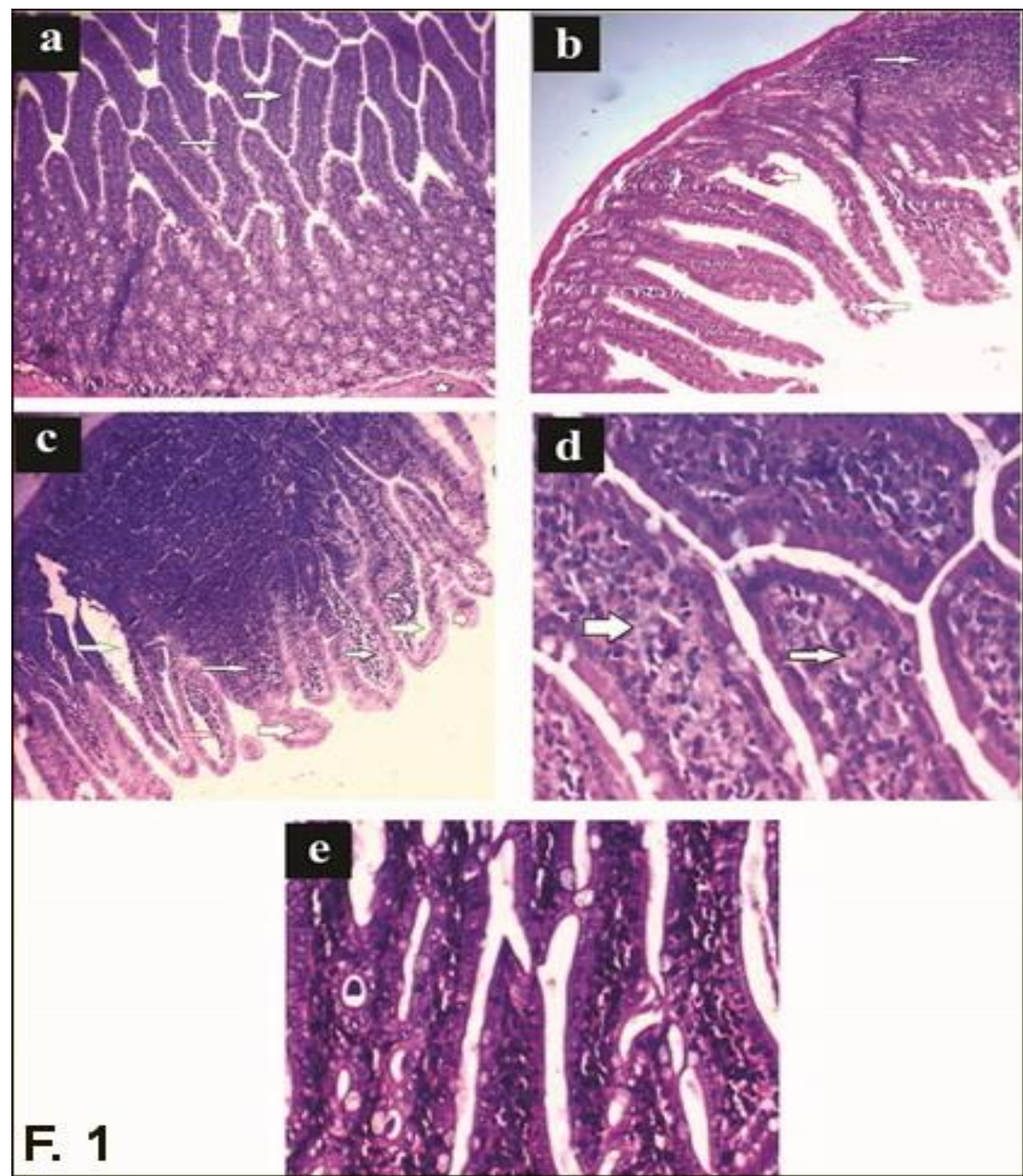


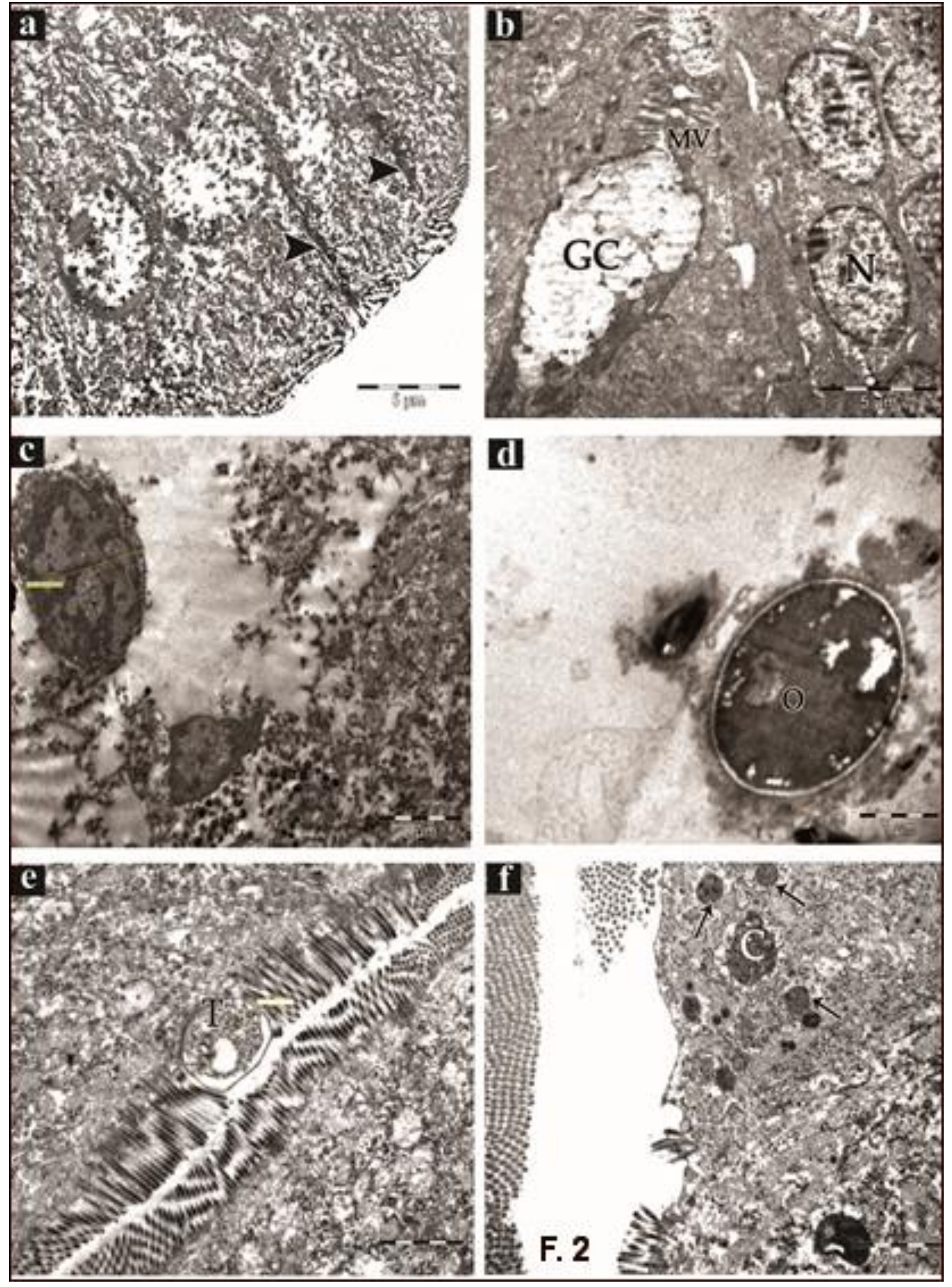

